\title{
Treatment of children with epistaxis: A 3 year follow up
}

\author{
Gundula Thiel*, Paul Joice and Mary-Louise Montague \\ Otolaryngology Unit, University of Edinburgh, Royal Hospital for Sick Children, UK
}

\begin{abstract}
Objective: The objective was to establish the long-term efficacy of treatment options and follow up in paediatric patients treated for epistaxis as well as parental satisfaction with ENT department care.

Patients and methods: A consecutive cohort of 82 children between the ages of 2 and 15 who were treated at a tertiary referral paediatric ENT centre in Scotland for epistaxis over a 14-month period were followed up with a retrospective case note review and postal questionnaire 3 years after discharge from ENT.

Results: 20 patients were treated with cautery and topical chlorhexidine-neomycin cream (Naseptin ${ }^{\circledR}$ ). 22 were treated with cream alone. Recurrence of epistaxis post discharge occurred in $74 \%$ of cases. The average score of parental satisfaction was high ( 8 on a VAS from 0-totally dissatisfied to 10 -totally satisfied). Recurrence rates and parental satisfaction were comparable between groups.

Conclusions: Recurrence of epistaxis was common, regardless or treatment method used. Neither treatment method appeared more effective than the other. Parental satisfaction was high, regardless of treatment modality or success.
\end{abstract}

\section{Introduction}

Epistaxis is one of the most common childhood presentations to the ENT department. It is estimated that by the age of 15 years, $64 \%$ of children have had at least one episode of epistaxis [1].

The aetiology is largely unknown, but crusting, bacterial colonisation and digital trauma are presumed factors [2]. There is little evidence regarding the efficacy of treatment. However, limited randomized controlled trials have demonstrated that Vaseline is ineffective [3] and Naseptin ${ }^{\circledR}$ is more effective than observation [4] and as effective as cautery alone [5] or combination treatment with cautery and Naseptin ${ }^{\circledR}[6]$.

Previous work on long-term outcome demonstrated a very high recurrence rate after 5 years (44-77\%), with the highest rate of recurrent epistaxis in children treated with Naseptin ${ }^{\circledR}$ cream and cautery [7].

The aim of the current study was to evaluate our own practice and attempt to determine the efficacy of previously applied treatment methods.

\section{Materials and methods}

A consecutive cohort of 82 children between the ages of 2 and 15 were treated for epistaxis at a tertiary paediatric centre in 2005-06 over a 14-month period. 3 years after discharge, we assessed these cases for efficacy of treatment and follow up pattern.

Case notes were reviewed retrospectively to identify initial and subsequent treatment and follow up regime. Parents/carers were then contacted by postal questionnaire to establish the recurrence of epistaxis after discharge from ENT care and assess satisfaction with ENT care.

Parents/carers were asked about the side, severity, duration and frequency of any recurrent epistaxis and how soon after discharge from ENT the recurrence occurred. It was also confirmed if further medical help was sought and if patients were referred back to ENT.
The overall satisfaction with the ENT service was assessed using a validated visual analogue scale ranging from 0 to $10(0=$ completely dissatisfied to $10=$ completely satisfied). Statistical analysis was undertaken using, a Fischer's exact two-tailed test.

Parents were given the option to request further ENT follow up with the questionnaire.

\section{Ethical considerations}

Quality Improvement Team and Caldicott approval were granted and the audit was discussed with the local ethics committee and specific approval not deemed necessary.

\section{Results and analysis}

Out of 82 treated patients, 65 sets of case notes were available (72\%). Questionnaires were sent to the parents/guardians of these patients and 42 completed questionnaires were returned (51\% of the total patient group, $65 \%$ response rate).

At first presentation to ENT, 30 patients were treated with Naseptin ${ }^{\circledR}$ nasal cream, 9 were treated with silver nitrate nasal cautery and 3 required no treatment.

After further follow up, a total of 22 patients had been treated with Naseptin ${ }^{\circledR}$ alone and 20 had received Naseptin ${ }^{\circledR}$ and cautery. We compared the outcomes of recurrence of epistaxis and patient satisfaction for these two groups.

Correspondence to: Dr. Gundula Thiel, University Department of Otolaryngology, Royal Infirmary of Edinburgh, Lauriston Building, Lauriston Place,Edinburgh, EH3 9EN, Tel.: 0131536 3740; Fax: 0131536 3744; E-mail: gundulathiel@doctors.org.uk

Key words: epistaxis, paediatrics, chlorhexidine/neomycin cream, cautery

Received: August 04, 2016; Accepted: August 26, 2016; Published: August 29, 2016 


\section{Results of questionnaire}

During the 3 year follow up period, 31 (74\%) patients suffered from recurrent epistaxis. Only $11(26 \%)$ of parents sought medical help for this problem however and $7(17 \%)$ of patients were referred back to ENT (Figures 1 and 2).

The recurrence free interval ranged from under 3 months to over a year (Figure 3).

Duration of epistaxis was mainly short lived, the majority lasting less than 10 minutes at a time (Figure 4). Episodes were also less frequent, occurring monthly or weekly (Figure 5).

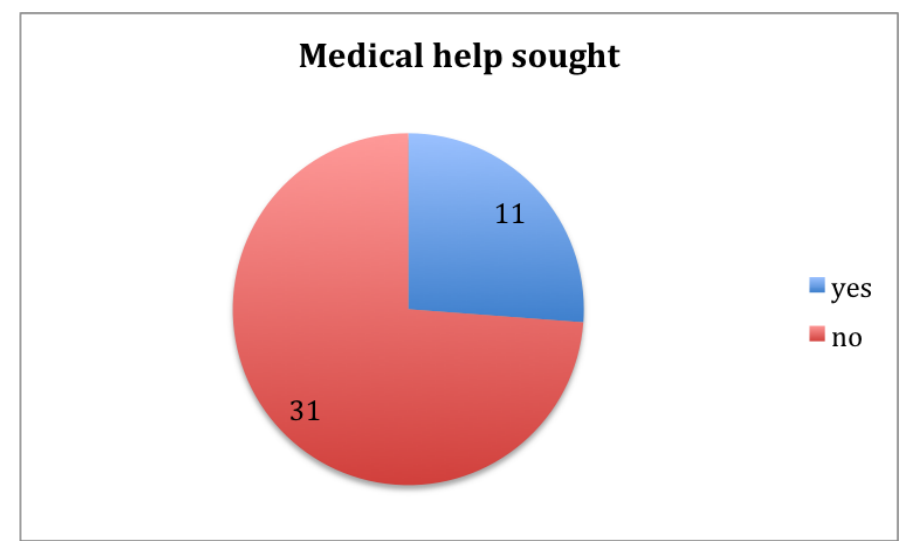

Figure 1. Further medical help sought.

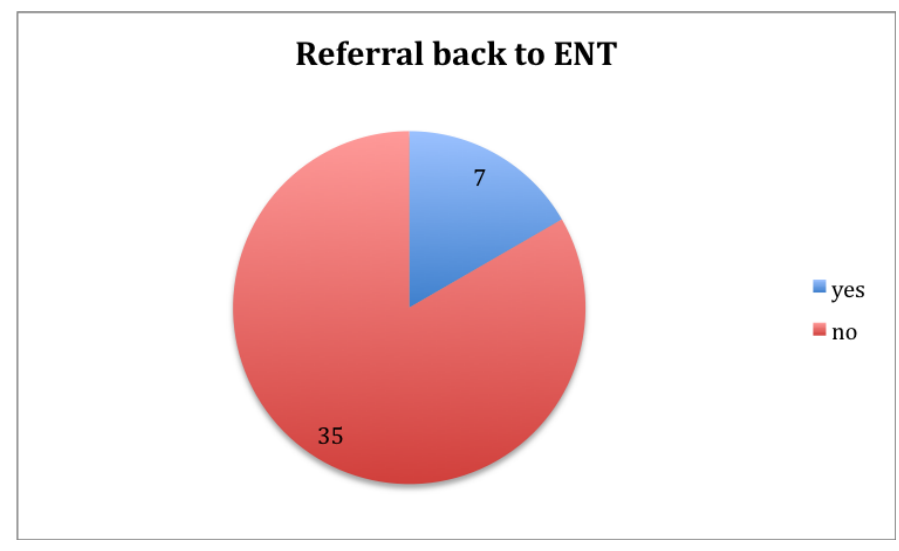

Figure 2. Patients referred back to ENT.

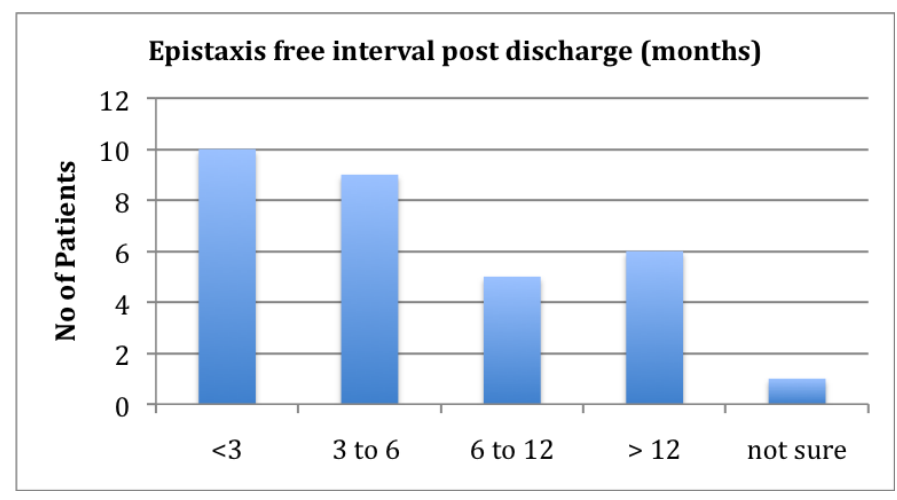

Figure 3. Epistaxis free interval post discharge from ENT.

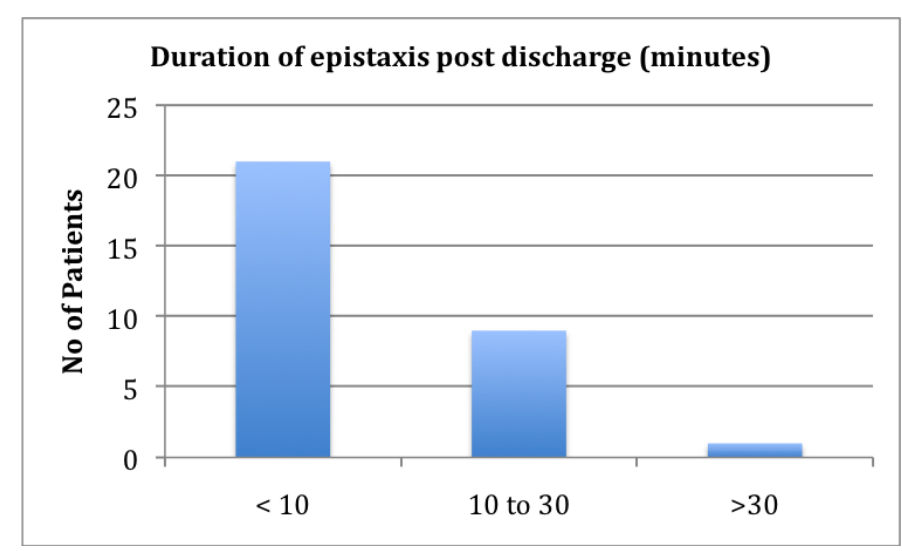

Figure 4. Duration of epistaxis post discharge.

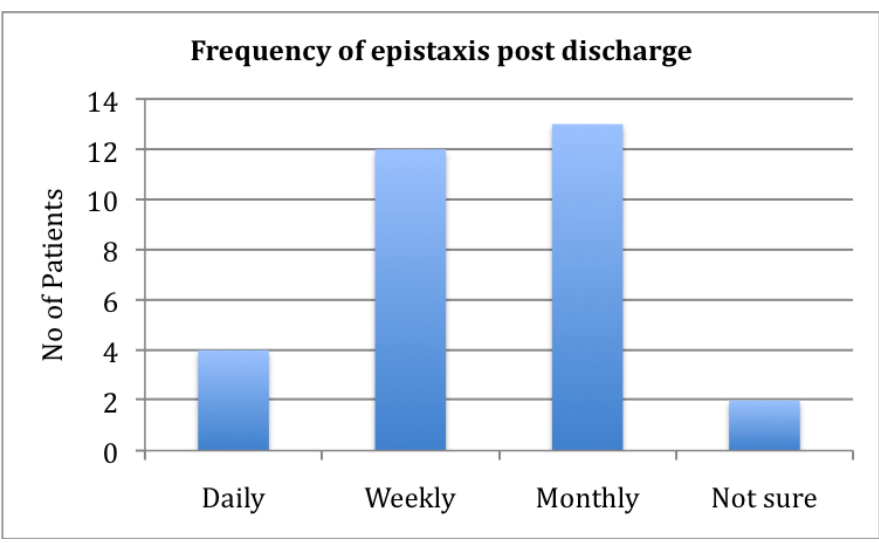

Figure 5. Frequency of epistaxis post discharge.

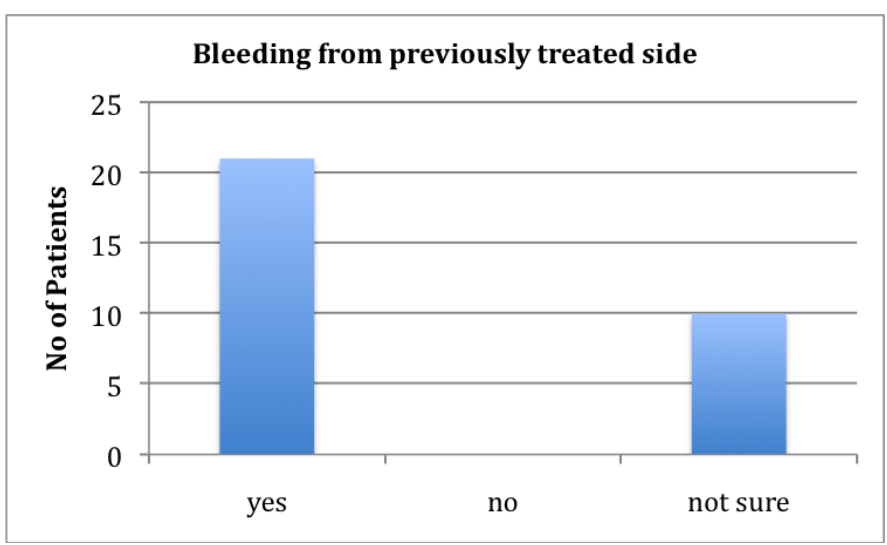

Figure 6. Bleeding from previously treated side.

Two thirds of patients had recurrence on the previously treated side and one third of parents could not remember if this was the case (Figure 6).

9 parents requested a further review after receiving the questionnaire.

20 children (48\%) received Naseptin ${ }^{\oplus}$ and silver nitrate cautery and $22(52 \%)$ were treated with Naseptin ${ }^{\otimes}$ cream alone.

In the first group, 13 (65\%) suffered recurrent epistaxis, while in the second group epistaxis recurred in $18(81 \%)$ of patients.

Overall $11(26 \%)$ patients sought medical help for the recurrence 
of epistaxis. $5(25 \%)$ were in the Naseptin ${ }^{\star}$ and cautery group and 6 (27\%) in the Naseptin only group. Of the 11 patients, 7 (17\%) were subsequently referred back to the ENT service. 3 were in the Naseptin ${ }^{\circ}$ and cautery group and 4 in the Naseptin ${ }^{\circ}$ alone group. There was no statistically significant difference between the groups in either of these parameters.

The rate of request for further review after discharge from ENT was almost twice as high in the group treated with cream alone although this was not statistically significant $(27.3 \%$ vs $15 \%, p=0,48)$ (Figure 7 ).

$36(86 \%)$ parents completed the VAS assessment of satisfaction with the treatment of their children by the ENT department. The mean score was 8 (Range 1.6- 10). There was no significant difference between the two treatment groups (Figure 8 ).

\section{Discussion}

In keeping with other published literature [7], we found the recurrence rate of epistaxis to be high at long-term review. Short-term reviews seem to indicate a significant but generally lower recurrence rate $[2,3,8]$.

We found no statistically significant difference between the rates of recurrence of each of the treatment groups, suggesting neither treatment was more effective than the other. However, no control of how patients were selected for each of the treatment arms was included in the study.

Very few parents sought further medical attention and fewer still

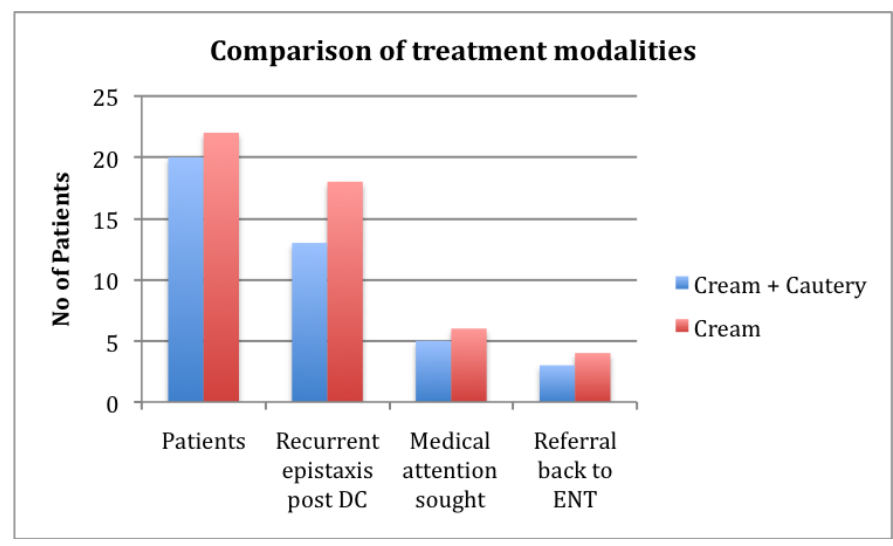

Figure 7. Comparison epistaxis treatment and follow-up.

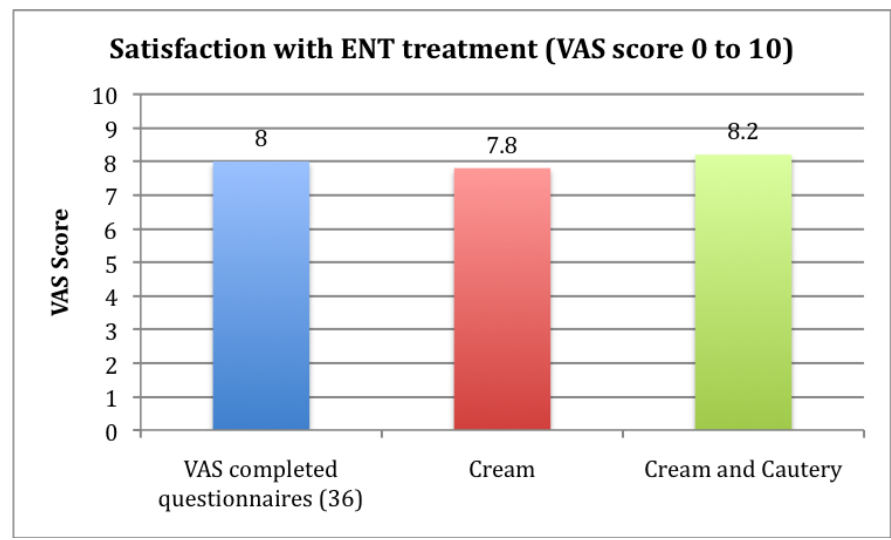

Figure 8. Parental satisfaction with ENT treatment. were referred back to the ENT department for further treatment even though recurrence rates were high. This may have reflected that parents felt they were now capable of dealing with their child's epistaxis, without the need for further medical input. Other contributing factors might be that the frequency and intensity of epistaxis is diminished after treatment, again enabling patients and parents to confidently treat recurring episodes independently. However, we were unable to establish patterns of epistaxis frequency and intensity pre-treatment to conclude on this.

Parental satisfaction appears to be high, regardless of the significant recurrence rate and independent of the treatment method employed. This high level of satisfaction might be due to reassurance obtained by the parents [4] from the initial consultation.

We acknowledge that the retrospective nature of this study does present some limitations. Randomisation did not take place and exact details as to severity and degree of epistaxis and possible comorbidities at primary visit were not available.

We are also aware of the limitations of a postal questionnaire, particularly the notoriously poor response rates. Our preference had been for telephone follow-up but this was over-ruled by the clinical governance team. Despite these limitations, we feel that the results overall will prove useful in proceeding to design a prospective randomised study to inform best outpatient management in a tertiary referral centre taking the above-mentioned factors into account.

\section{Conclusion}

Cautery and the application of topical cream $\left(\right.$ Naseptin $\left.{ }^{\circledR}\right)$ are current treatment options for idiopathic childhood epistaxis. Longterm epistaxis recurrence rates are high however and no method is clearly more effective than the other. Parental satisfaction is high, regardless of which treatment method is utilised and further medical treatment is rarely sought.

\section{Summary}

\section{What is already known on the subject}

- Epistaxis is one of the most common childhood presentations to the ENT department.

- Established treatment methods chiefly consist of application of Naseptin ${ }^{\circledR}$ cream alone or Naseptin ${ }^{\circledR}$ cream and cautery.

- One long term follow up study showed high recurrence rates 5 years after treatment.

\section{What this paper adds to the subject}

- Recurrence rates are high with $74 \%$ at long-term follow up.

- Recurrence rates are comparable regardless of treatment method employed.

- Frequency and severity of further epistaxis seems diminished.

- Further medical advice is rarely sought.

Parental satisfaction is high, regardless of success of treatment and treatment method.

\section{References}

1. Petruson B (1979) Epistaxis in children: causes, diagnosis and treatment. Rhinology 17: 83-90.

2. Burton MJ, Dorée CJ (2004) Interventions for recurrent idiopathic epistaxis 
(nosebleeds) in children. Cochrane Database Syst Rev CD004461. [Crossref]

3. Loughran S, Spinou E, Clement WA, Cathcart R, Kubba, H, et al. (2004) A prospective, single-blind, randomized controlled trial of petroleum jelly for recurrent paediatric epistaxis. Clin Otolaryngol Allied Sci 29: 266-9. [Crossref]

4. Kubba H, MacAndie C, Botma M, Robison J, O’Donnell M, et al. (2001) A prospective, single-blind, randomized controlled trial of antiseptic cream for recurrent epistaxis in childhood. Clin Otolaryngol Allied Sci 26: 465-468. [Crossref]

5. Ruddy J, Proops DW, Pearman K, Ruddy H (1991) Management of epistaxis in children. Int J Pediatr Otorhinolaryngol 21: 139-142. [Crossref]
6. Murthy P, Nilssen EL, Rao S (1999) A randomised clinical trial of antiseptic nasal carrier cream and silver nitrate cautery in the treatment of recurrent anterior epistaxis. Clin Otolaryngol Allied Sci 24:228-31. [Crossref]

7. Robertson S, Kubba H (2008) Long-term effectiveness of antiseptic cream for recurren epistaxis in childhood: five-year follow up of a randomised, controlled trial. $J$ Laryngol Otol 122: 1084-1087. [Crossref]

8. Calder N, Kang N, Fraser L, Kunanandam T, Montgomery J, et al. (2009) A doubleblind randomized controlled trial of management of recurrent nosebleeds in children. Otolaryngol Head Neck Surg 140: 670-674. [Crossref]

Copyright: (C2016 Thiel G. This is an open-access article distributed under the terms of the Creative Commons Attribution License, which permits unrestricted use, distribution, and reproduction in any medium, provided the original author and source are credited. 